\begin{tabular}{|l|l|}
\hline Title: & $\begin{array}{l}\text { Performance of punching shear reinforcement under gravity loading: Influence of } \\
\text { type and detailing }\end{array}$ \\
\hline Authors: & Einpaul J., Brantschen F., Fernández Ruiz M., Muttoni A. \\
\hline Published in: & ACI Structural Journal \\
\hline DOI & $10.14359 / 51688630$ \\
\hline $\begin{array}{l}\text { Volume: } \\
\text { Pages: }\end{array}$ & $\begin{array}{l}\text { Vol. } 113, \text { No } 4 \\
\text { pp. 827-838 }\end{array}$ \\
\hline City, country: & Farmington Hills, USA \\
\hline Year of publication: & 2016 \\
\hline Type of publication: & Peer reviewed journal article \\
\hline
\end{tabular}

Please quote as:

Einpaul J., Brantschen F., Fernández Ruiz M., Muttoni A., Performance of punching shear reinforcement under gravity loading: Influence of type and detailing, ACI Structural Journal, Vol. 113, No 4, Farmington Hills, USA, 2016, pp. 827-838. 


\title{
Performance of Punching Shear Reinforcement under Gravity Loading: Influence of Type and Detailing
}

\author{
by Jürgen Einpaul, Fabio Brantschen, Miguel Fernández Ruiz, and Aurelio Muttoni
}

\begin{abstract}
The performance of 11 different shear reinforcement systems against punching of inner slab-column connections under gravity loading was compared on the basis of experiments on 12 full-scale specimens, eight of them newly reported. The slab geometry and flexural reinforcement ratio (1.5) were kept constant. The shear reinforcement systems included different layouts of double-headed studs, individual links, bent-up bars, and bonded post-installed reinforcement. All the systems were found to increase both the strength and the deformation capacity of the members but exhibited varying performances. The factors influencing the maximum punching strength of different systems, such as the layout and the anchorage conditions of the transverse reinforcement units, are described and analyzed. The mechanical model of the Critical Shear Crack Theory is used to explain the observed differences and provide design guidance. Comparisons to the codes of practice (ACI 318, Eurocode 2, and Model Code 2010) are also presented.
\end{abstract}

Keywords: critical shear crack theory; interior slab-column connections; punching shear; shear reinforcement.

\section{INTRODUCTION}

Punching failures around columns often govern the design at the ultimate limit state of flat plates and footings. The ways to enhance the punching capacity under gravity loads include enlarging the supported area or slab thickness (for instance, adding column capitals or drop panels), increasing the concrete strength (or using fiber-reinforced materials), or using shear reinforcement. ${ }^{1,2}$ The first methods are not always feasible due to practical or architectural considerations, and using high-performance materials in the whole slab may not be economically justified; thus, shear reinforcement has been established as a common solution that allows constructing slender slabs by avoiding local punching problems. Post-installed shear reinforcement can also be used to strengthen existing slabs with insufficient punching shear capacity. Several different shear reinforcement systems are currently used, including bent-up bars, single- or multiple-leg stirrups, double-headed studs, and other kind of preor post-installed reinforcing bars, vertical or inclined (Fig. 1). The performances of these systems, especially the maximum punching strength in the case of large amounts of shear reinforcement, have been reported quite different depending on the anchorage properties and detailing of the shear units. ${ }^{2}$ Some codes of practice acknowledge these differences (such as ACI $318-14^{3}$ and Model Code $2010^{4}$ ), whereas others (Eurocode $2^{5}$ ) do not explicitly account for them.

The crucial issue in designing and assembling shear reinforcement is finding a compromise between efficient anchorage and the ease of installation of the transverse double-headed studs:

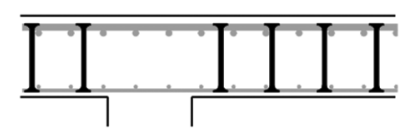

individual stirrups:

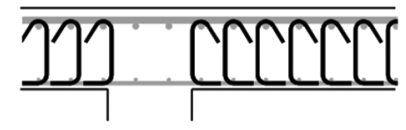

continuous cages:

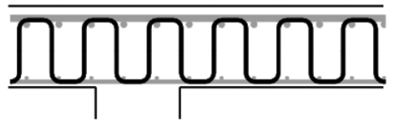

continuous cages that do not enclose main reinforcement:

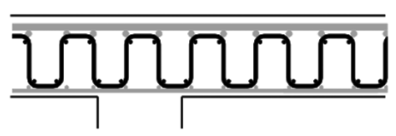

two-leg stirrups:

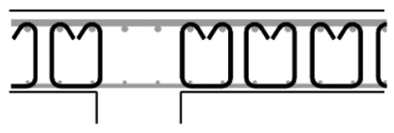

bent-up bars:

post-installed concrete screws:
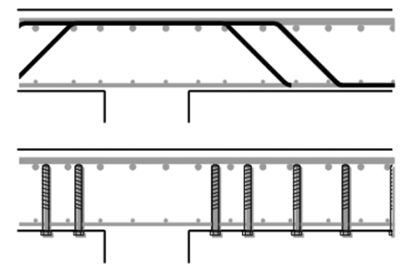

post-installed shear bolts:

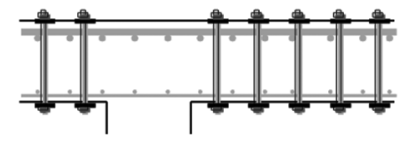

Fig. 1-Examples of punching reinforcement systems.

reinforcement units. A considerable amount of research has been performed in the field and several shear reinforcement systems have been experimentally investigated. Other-than-conventional solutions composed of vertical stirrups or headed studs, unusual systems, such as stirrups that do not embrace main reinforcement, ${ }^{6-8}$ combinations of continuous stirrups and bent-up bars, ${ }^{9,10}$ inclined stirrups, ${ }^{11}$ as well as offcuts of steel I-sections ${ }^{12}$ have been studied. Also, the influence of placing the shear reinforcement in a cruciform or a radial pattern ${ }^{13,14}$ and the efficiency of postinstalled shear reinforcement ${ }^{15-17}$ have been studied. The tests have shown that all types of shear reinforcement improve the punching capacity, but, on the basis of available experimental

ACI Structural Journal, V. 113, No. 4, July-August 2016.

MS No. S-2015-142.R2, doi: 10.14359/51688630, received September 1, 2015, and reviewed under Institute publication policies. Copyright (C) 2016, American Concrete Institute. All rights reserved, including the making of copies unless permission is obtained from the copyright proprietors. Pertinent discussion including author's closure, if any, will be published ten months from this journal's date if the discussion is received within four months of the paper's print publication. 
(a) Punching failure of slabs without shear reinforcement (b) Failure within the shear reinforced area

Governing for dimensioning the amount of shear reinforcement.
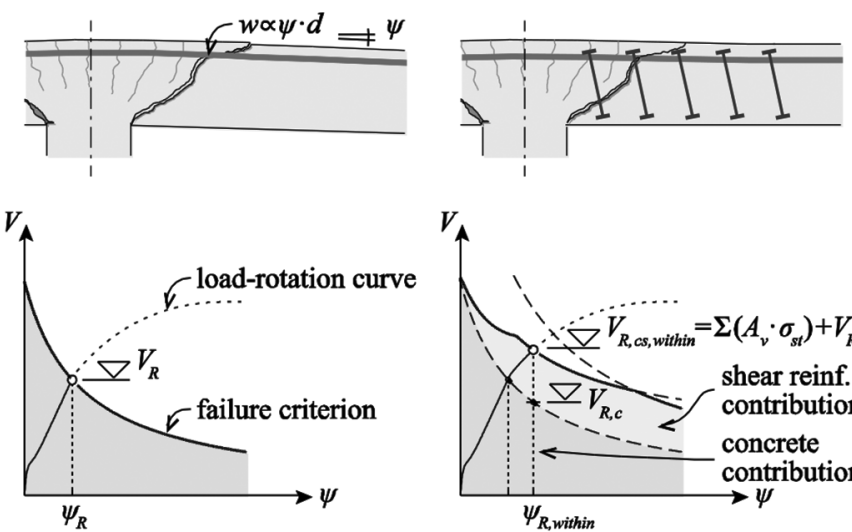

(c) Maximum punching capacity inside the shear reinforced area

Governing for the maximum achievable punching strength for the chosen slab geometry, flexural reinforcement and shear reinforcement system.
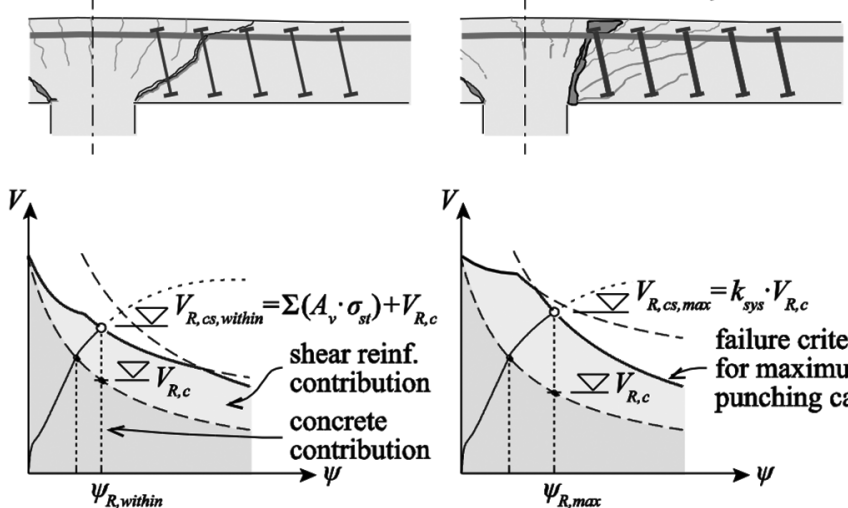

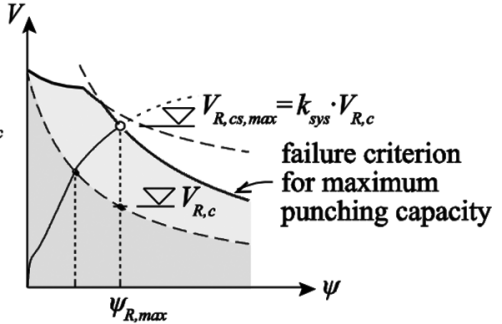

(d) Failure outside of the shear reinforced area

Governing for choosing the extent of the shear reinforced area.
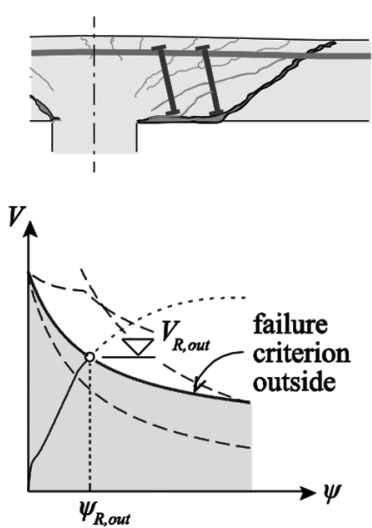

Fig. 2-Punching failure modes of flat slabs.

data, it is difficult to compare the efficiency of different systems because of the different parameters (slab thickness and span, column size, flexural reinforcement, load introduction system) used in the tests. In addition, many of the tests have been performed on thin slabs and therefore cannot be considered representative of real structures. This paper presents an experimental campaign on full-scale slab specimens equipped with different types of shear reinforcement, whereas all the other parameters are kept similar or constant. The results are discussed and analyzed on the basis of the mechanical model of the Critical Shear Crack Theory (CSCT).

The CSCT states that the punching shear strength of slabs without shear reinforcement is a function of the opening of critical crack $w$, which is assumed to be proportional to the product of slab rotation $\psi$ and effective depth of the slab $d$ (Fig. 2(a); refer to Appendix $\mathrm{A}^{*}$ for design formulas). The reduction of the shear strength with increasing slab deformation is justified by the presence of wider cracks that weaken the diagonal shear-carrying strut around the column. Considering the slab rotation as the governing parameter allows directly accounting for the reduced strength of more slender slabs that show larger deformations for the same level of applied shear force. ${ }^{18}$ The CSCT failure criterion also directly accounts for the size effect (reduced unitary shear strength for thicker slabs). ${ }^{1}$

The CSCT was extended by Fernández Ruiz and Muttoni ${ }^{19}$ to be applicable on slabs with shear reinforcement. Different failure modes that may occur in such slabs are summarized in Fig. 2(b) to (e). Placing shear reinforcement that intersects the critical crack allows for carrying part of the shear force with transverse reinforcement. The total punching capacity $V_{R}$ can thus be found by summing the concrete contribution ( $V_{R, c}$ in Fig. 2(b) - note that it decreases with increasing slab rotation) and the forces in shear reinforcement units. These latter forces depend on the strains in the transverse rein-

${ }^{*}$ The Appendix is available at www.concrete.org/publications in PDF format, appended to the online version of the published paper. It is also available in hard copy from ACI headquarters for a fee equal to the cost of reproduction plus handling at the time of the request. forcement units, which increase for increasing slab rotation due to larger openings of the critical shear crack that these elements intersect (Fig. 2(b)). The steel contribution is also limited by the yield strength of shear reinforcement, as well as anchorage conditions of transverse reinforcement units for some reinforcing systems. ${ }^{19}$ The failure occurs when the slab rotation reaches a critical value $\left(\psi_{R, \text { within }}\right)$ with a sudden loss of concrete capacity and subsequent anchorage failure of transverse reinforcement units or steel rupture. This failure mode is referred to as failure within the shear reinforced area and it is usually governing for low or moderate amounts of shear reinforcement.

In slender slabs, if a large amount of shear reinforcement is provided, punching may also occur before shear reinforcement reaches yielding due to a failure of the diagonal compression struts developing between the edge of the supported area and the top anchorage zones of the shear reinforcement units (Fig. 2(c)). ${ }^{2,19}$ According to the CSCT $^{1}$ (and the punching provisions of Model Code $2010^{4}$ that are based on this model), the punching capacity in this failure mode is influenced by the same parameters as for punching without shear reinforcement. This is justified because both failure modes are governed by the capacity of concrete to carry shear forces (that is, governed by its cracking state). It should be noted that the maximum punching capacity is assumed to be independent of the amount of shear reinforcement (no strength increase above a certain amount of provided shear reinforcement). However, positioning, detailing, and anchorage properties of shear reinforcement units influence the capacity by controlling the locations and transverse strains of the concrete struts. This is accounted for in the CSCT by multiplying the concrete contribution failure criterion $\left(V_{R, c}\right)$ with factor $k_{s y s}$ (Fig. 2(c)) that depends on the performance of the shear reinforcement system. The value of $k_{s y s}$ should be determined by specific testing for each system.

If a relatively large amount of shear reinforcement is provided in a rather small area, punching failures may also occur outside of the shear-reinforced zone (Fig. 2(d)). In this case, that zone can be considered a supported area with a 
Table 1-Main parameters of test specimens

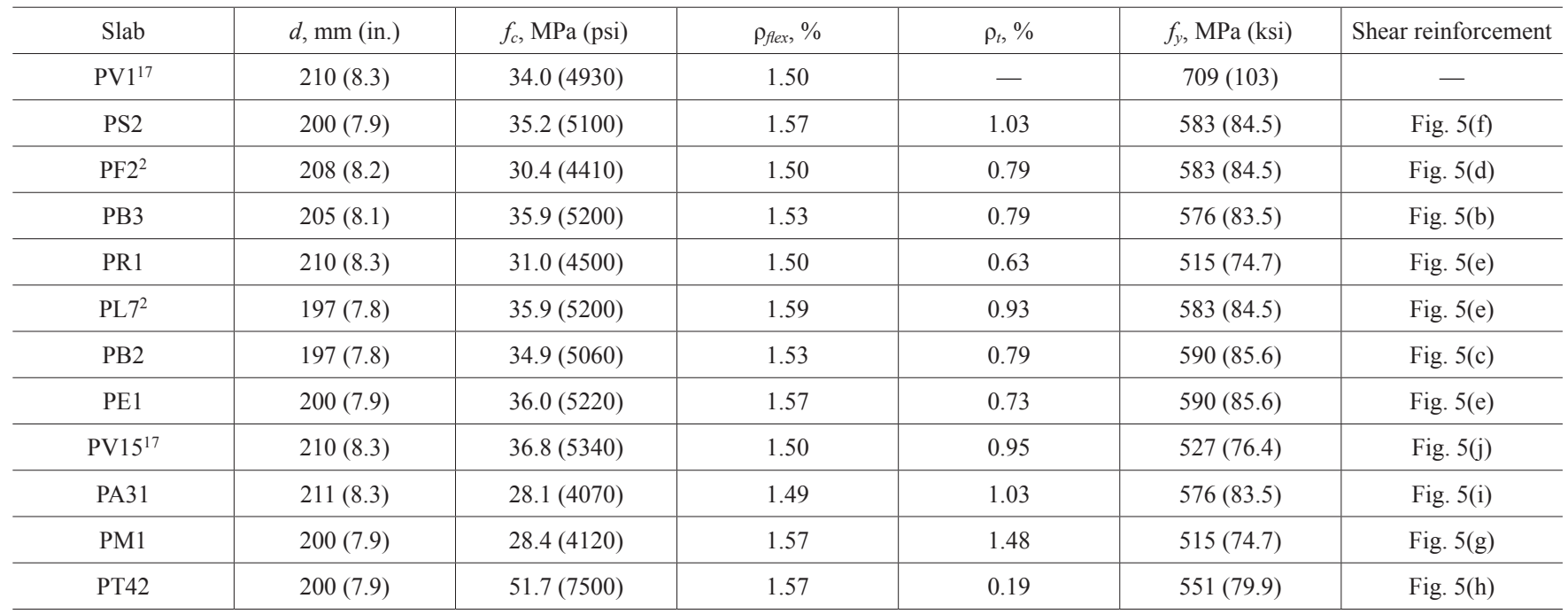

Note: Shear reinforcement ratio for radial and cruciform layout is defined as $\rho_{t}=A_{v} /\left[b_{0, \text { rnd }} \cdot \max \left(s_{0}+s_{1} / 2 ; s_{1}\right)\right]$, where $\Sigma A_{v}$ is the total cross-section area of shear reinforcement units in the innermost perimeter; $b_{0, \text { rnd }}$ is defined in Fig. 8; and $s_{0}$ and $s_{1}$ are defined in Fig. 6.

control perimeter outside of the last perimeter of transverse reinforcement units.

Design for punching shear should be performed by considering all the above-mentioned failure modes. Failure within the shear-reinforced area governs for selecting the amount of shear reinforcement (the diameter and the number of reinforcement units on a perimeter), and failure outside of the shear reinforced area dictates the required number of perimeters. Failure of the concrete struts (the maximum punching shear strength) limits the maximum achievable punching strength for each system. This failure mode (and its associated factor $k_{s y s}$ ) is thus instrumental to determine the applicability of a given system to a particular case. Therefore, this failure mode was targeted in the design of the test specimens of the present campaign.

The predicted influence of the amount of shear reinforcement on the punching strength of a flat plate is shown in Fig. 3. According to the provisions of Model Code 2010, ${ }^{4}$ three regimes depending on the shear reinforcement ratio can be distinguished corresponding to failures within the shear-reinforced area without full activation of shear reinforcement, failures within the shear-reinforced area with full yielding of shear reinforcement (Fig. 2(b)), and the maximum punching capacity (Fig. 2(c)). The normalized punching shear capacity depends on the type of shear reinforcement only in the case of reaching the maximum strength for a given system (stirrups or studs in Fig. 3). Also, in ACI $318,{ }^{3}$ the type of shear reinforcement has an influence on the maximum achievable punching strength (stirrup and stud shear reinforcement as well as structural steel shearheads are distinguished).

\section{RESEARCH SIGNIFICANCE}

This paper presents new experimental evidence of the performances of different shear reinforcement systems. The full-size test specimens were provided with high amounts of flexural and transverse reinforcement to avoid flexural failures and to achieve the maximum possible strength and deformation capacity of each system. The results are easily comparable as the other properties of the specimens were kept constant. The experiments provide clear evidence that the punching performance and strength of flat plates depends significantly on the type of shear reinforcement. This can be explained by the differences in detailing and properties of the transverse reinforcement units.

\section{EXPERIMENTAL PROGRAM}

The experimental program included testing of eight new punching specimens equipped with different types of shear reinforcement. All slabs had identical geometries and flexural reinforcement as well as similar material properties (common European reinforcing steel and normal-strength concrete). The thickness and slenderness ratios of the specimens were selected to model typical slab-column connections in buildings. Four specimens with similar properties from previous test campaigns of the authors are also included in the comparison.

\section{Parameters}

The main parameters of the tested slabs are presented in Table 1. All the slabs were square with a thickness of $250 \mathrm{~mm}$ ( $9.8 \mathrm{in}$.) and a side length of $3 \mathrm{~m}(9.8 \mathrm{ft})$. The size of the square support region was $260 \mathrm{~mm}$ (10.2 in.). Concrete cylinder strength (measured on $160 \times 320 \mathrm{~mm}$ [6.3 x 12.6 in.] samples) was kept between 28.1 and $36.8 \mathrm{MPa}$ (4070 and $5340 \mathrm{psi}$ ) for all slabs except PT42 (where $51.7 \mathrm{MPa}[7000$ psi] concrete was used). The maximum size of the aggregate (mainly limestone alluvial gravel) was $d_{g}=16 \mathrm{~mm}(5 / 8 \mathrm{in}$.) for all slabs. The nominal flexural reinforcement ratio for the investigated slabs was 1.50 with $\varnothing 20 \mathrm{~mm}(0.79$ in.) reinforcing bars with a spacing of $100 \mathrm{~mm}$ (3.9 in.). The measured effective depths varied from 197 to $211 \mathrm{~mm}$ (7.8 to $8.3 \mathrm{in}$.) (refer to Table 1 for details). The yield strength of the tensile reinforcing steel (between 515 and $709 \mathrm{MPa}$ [74.7 and $103 \mathrm{ksi}$ ]) was determined experimentally for all specimens. Compression reinforcement consisted of $\varnothing 10 \mathrm{~mm}$ (0.39 in.) bars with spacing equal to that of the tension reinforcement. The nominal concrete cover both on the top and on the bottom face of the slabs was $20 \mathrm{~mm}(0.8 \mathrm{in}$.). 


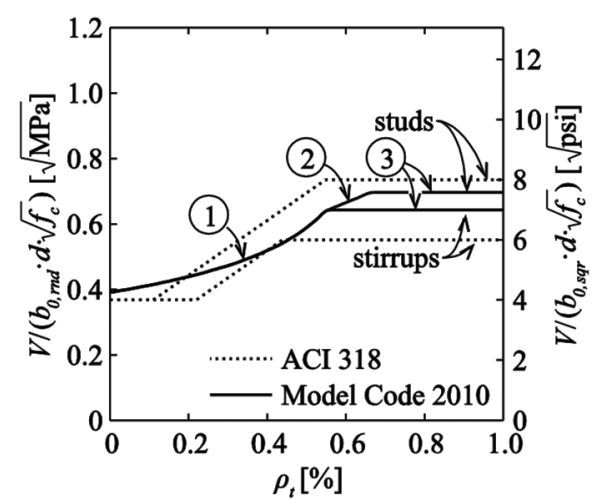

(1) Failure within before shear reinforcement yields

(2) Failure within with shear reinforcement yielding

(3) Maximum punching shear capacity

Fig. 3-Influence of amount of shear reinforcement on punching strength (parameters: slab span $7.3 \mathrm{~m}$ [24 ft.]; $\mathrm{d}=$ $210 \mathrm{~mm}$ [8.3 in.]; column size $260 \times 260 \mathrm{~mm}$ [10.2 in.]; $\rho_{\text {flex }}$ $=1.5 \% ; \mathrm{f}_{\mathrm{y}}=550 \mathrm{MPa}[80 \mathrm{ksi}] ; \mathrm{f}_{\mathrm{yt}}=450 \mathrm{MPa}[65 \mathrm{ksi}] ; \mathrm{f}_{\mathrm{c}}=$ $35 \mathrm{MPa}$ [5080 psi]; $\mathrm{d}_{\mathrm{g}}=16 \mathrm{~mm}$ [5/8 in.]).

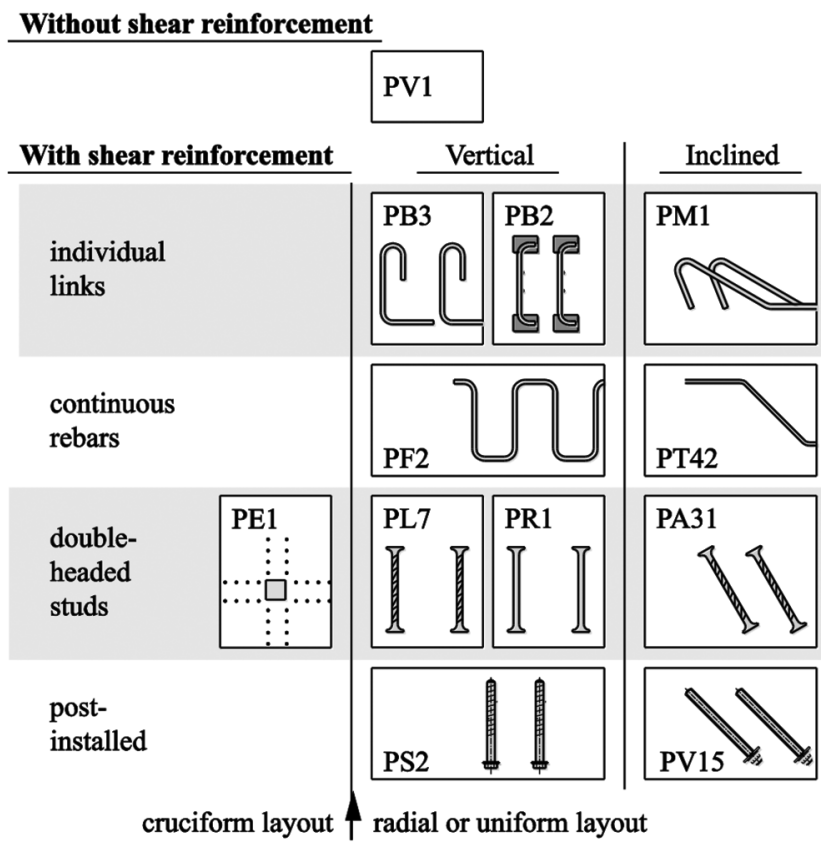

Fig. 4-Overview of test program.

Eleven specimens (eight slabs tested within the present research and three previously published specimens) were equipped with different types of shear reinforcement. The investigation focused on comparing the maximum performance of reinforcement systems with different anchorage conditions, inclinations and layouts of the shear units, and extents of the shear-reinforced area. An overview of the campaign is shown in Fig. 4. Specimen PV1 ${ }^{17}$ (Fig. 5(a)) was a reference slab with no shear reinforcement. In the series of slabs with vertical shear reinforcement:

1. PB3 was reinforced with individual hooked links (Fig. 5(b));

2.InPB2, the anchorage of the individual links was enhanced by enclosing the end hooks in blocks of ultra-high-performance fiber-reinforced concrete (UHPFRC) ${ }^{20}$ (compressive strength $150 \mathrm{MPa}[21,800 \mathrm{psi}]$, tensile strength $10 \mathrm{MPa}$ [1450 psi], and $3 \%$ fiber content [ø0.16 mm (0.006 in.); fiber slenderness ratio 80)] (Fig. 5(c)); (a) PV1

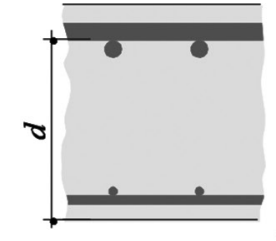

(c) PB2

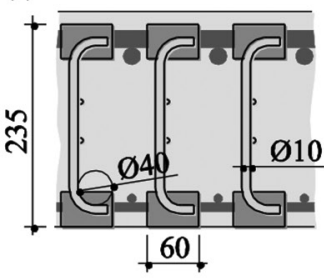

(e) PL7, PR1, PE1

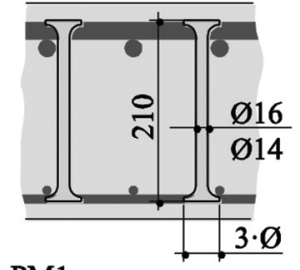

(g) PM1

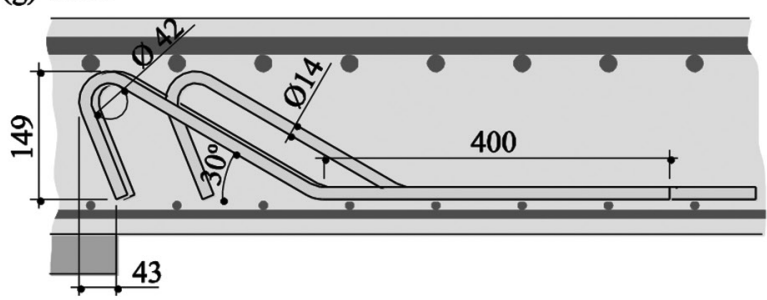

(h) PT42

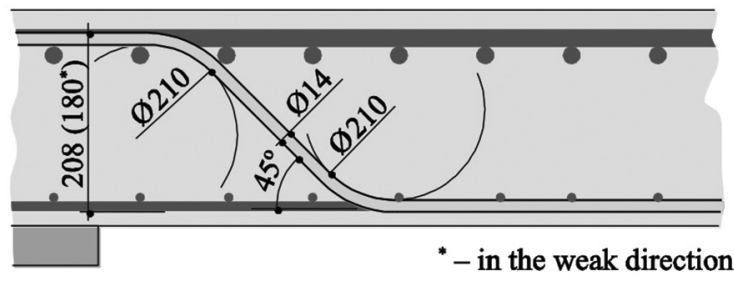

(i) PA31

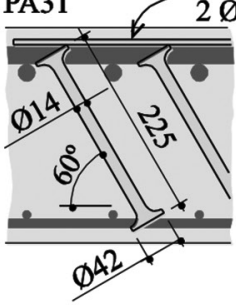

connecting bars

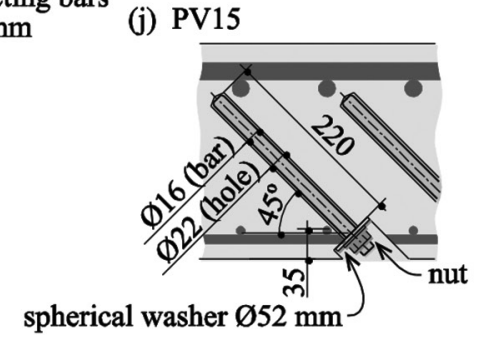

Fig. 5-Details of shear reinforcement. (Note: dimensions in $\mathrm{mm} ; 1 \mathrm{~mm}=0.039 \mathrm{in}$.)

3. PF2 was reinforced with continuous cages of stirrups (Fig. 5(d));

4. PL7 was reinforced with double-headed studs with deformed shafts, and PR1 with studs with smooth shafts (Fig. 5(e)); and

5. PS2 had post-installed shear reinforcement-vertical screws were screwed into pre-drilled holes that were filled with two-component epoxy adhesive (Fig. 5(f)). 
Table 2-Layout, diameter, and spacing of shear reinforcement units

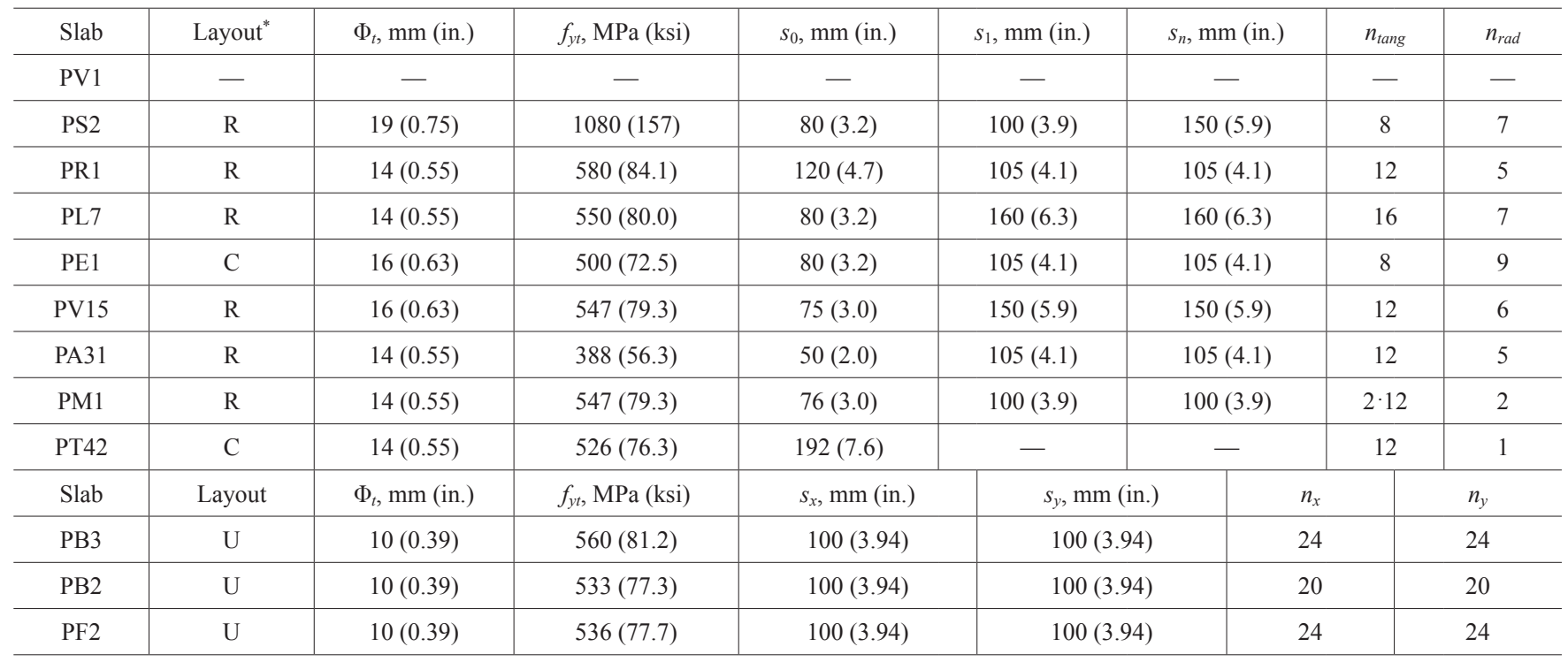

" $\mathrm{R}$ is radial; $\mathrm{C}$ is cruciform; and $\mathrm{U}$ is uniform (refer to Fig. 6).

(a)

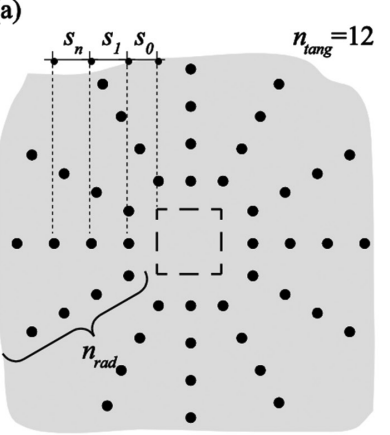

(c)

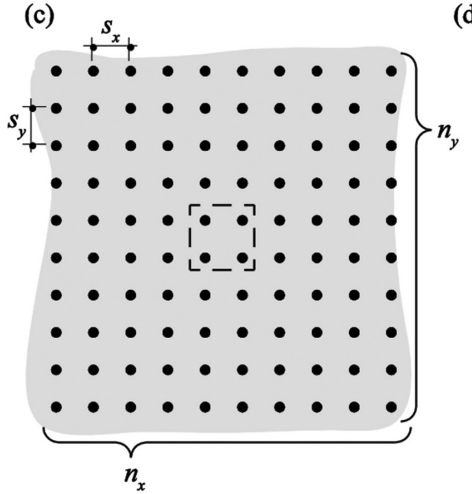

(b)

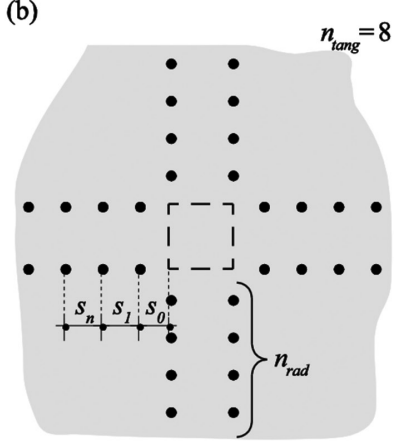

(d)

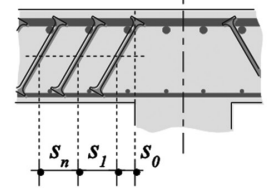

Fig. 6-Layout and parameters of shear reinforcement: (a) radial placement; (b) cruciform placement; (c) uniform placement; and (d) definition of bar spacing for inclined shear reinforcement.

The second series had inclined shear reinforcement. Inclined reinforcement units intersect the diagonal shear cracks at steeper angles and are thus able to control the crack openings more efficiently. ${ }^{19}$ Such reinforcement has also an increased anchorage length.

1. PM1 was reinforced with radially arranged noncontinuous bent-up bars (Fig. 5(g)), with double the number of bars in the first perimeter than in the second;
2. PT42 was reinforced with traditional bent-up bars on one perimeter (Fig. 5(h));

3. PA31 was reinforced with inclined studs (Fig. 5(i)), otherwise similar to PL7; and

4. PV15 had post-installed inclined deformed bars with threaded ends that were fixed into drilled holes with epoxy adhesive and anchored in the bottom end with a spherical washer and a nut (Fig. 5(j)) (more details can be found in Fernández Ruiz et al. ${ }^{17}$ ).

The third varied parameter was the layout of the transverse bars (the different layout patterns of the shear reinforcement units [radial, cruciform, and uniform]) and are shown in Fig. 6:

1. Specimens PS2, PR1, PL7, PV15, PA31, and PM1 had radial arrangement of the shear reinforcement (Fig. 6(a)) according to European practice;

2. PE1 was reinforced with double-headed studs arranged in a cruciform pattern according to American practice (Fig. 6(b)); and

3. In Specimens PB3, PB2, and PF2, the shear reinforcement units were distributed uniformly (Fig. 6(c)).

The number of the transverse units and their spacing are presented in Table 2. The amount of shear reinforcement was selected to achieve the highest possible performance of a given system and reach to the failure of the concrete struts (maximum punching capacity in Fig. 3). Detailing of most reinforcement systems complied with the recommendations of the codes of practice, ${ }^{3-5}$ except for the post-installed reinforcement and the location of the first stud perimeter in Specimen PR1.

\section{Test setup}

Load was applied on specimens at eight points located $120 \mathrm{~mm}$ (4.7 in.) from the slab edge by tension rods passing through cylindrical holes (Fig. 7). Each two rods on one side of the slab were connected to a spreader element that was pulled downwards by a hydraulic jack under the strong laboratory floor. The oil pressure in the jacks was increased by 


\begin{tabular}{|c|c|c|c|c|c|c|c|}
\hline Slab & $V_{R}, \mathrm{kN}$ (kip) & $\psi_{R}, \operatorname{mrad}($ mean) & Failure mode & $\frac{V_{R}}{b_{0, \text { rnd }} d \sqrt{f_{c}}}, \sqrt{\mathrm{MPa}}$ & $\frac{V_{R}}{b_{0, s q r} d \sqrt{f_{c}}}, \sqrt{\mathrm{psi}}$ & $k_{s y s}{ }^{*}$ & $k_{\max }^{\dagger}$ \\
\hline PV1 & 974 (219) & 7.6 & - & 0.468 & 5.63 & - & - \\
\hline PS2 & $1383(311)$ & 13.6 & Within/max & 0.699 & 8.41 & $(2.02)$ & (1.42) \\
\hline PF2 & $1567(352)$ & 15.0 & Maximum & 0.807 & 9.72 & 2.58 & 1.62 \\
\hline PL7 & 1773 (399) & 27.6 & Maximum & 0.905 & 10.90 & 3.62 & 1.85 \\
\hline PB2 & $1803(405)$ & 25.1 & Maximum & 0.934 & 11.25 & 3.82 & 1.89 \\
\hline PE1 & 1857 (417) & 27.4 & Maximum & 0.928 & 11.17 & 3.84 & 1.89 \\
\hline PV15 & $1609(362)$ & 24.4 & Maximum & 0.743 & 8.95 & 2.60 & 1.54 \\
\hline PT42 & 1283 (289) & 11.3 & Outside & 0.535 & 6.44 & $(1.40)$ & (1.16) \\
\hline
\end{tabular}

"Reference 4.

'Reference 5 .

Note: In case of slabs where maximum punching capacity was not attained, $k_{s y s}$ and $k_{\max }$ values are given in parentheses. Higher values could potentially have been reached if other failure modes had been avoided.

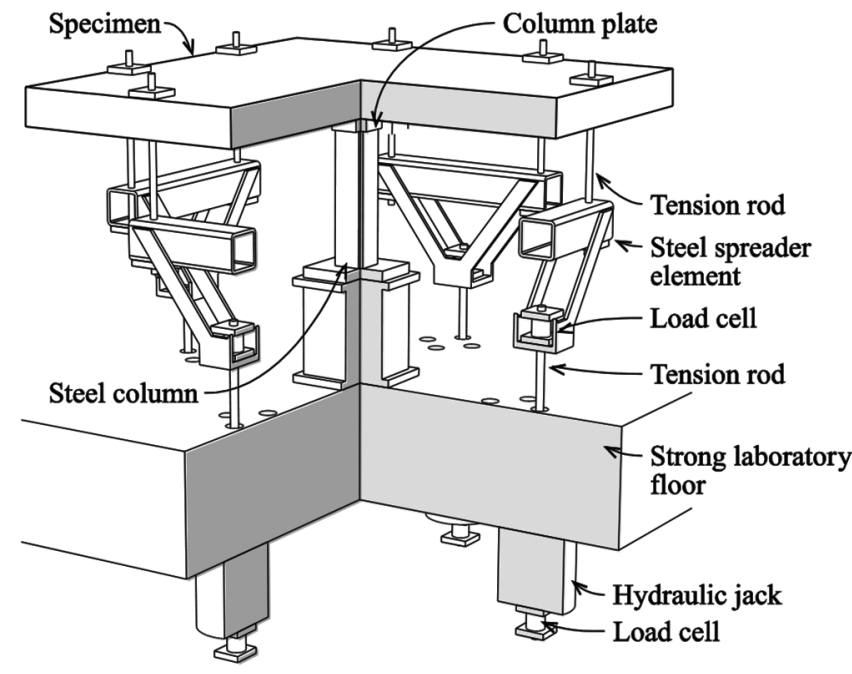

Fig. 7-Test setup.

manual pumping until failure so that the equal force in all four jacks increased with a constant rate of approximately $25 \mathrm{kN} /$ $\min (5.6 \mathrm{kip} / \mathrm{min})$. More information about the test setup can be found elsewhere. ${ }^{2}$ A different setup was used for Specimens PV1 and PV15, where the load was applied with one jack in the center and the slab was fixed to a supporting system at eight points close to the edge (a full description is given in Fernández Ruiz et al. ${ }^{17}$ ). The punching force was measured with a load cell either on the support column or as a sum of forces measured with load cells between the hydraulic jacks and strong floor. The self-weight of the slab and the loading system was later added to the measured force.

Rotations of the slabs were measured with four inclinometers placed on the top face of the slab on main axes 100 or $120 \mathrm{~mm}$ (3.9 to $4.7 \mathrm{in}$.) from the slab edge. After the tests, the slabs were saw-cut along the weak axis (parallel to the third layer of reinforcement) and the cracking patterns on the cut surfaces as well as on the top faces of the slab were recorded.

\section{Main results}

The failure of all specimens with shear reinforcement occurred either in the vicinity of the edge of the column plate (in all the cases with steeper failure cones than in the reference slab without shear reinforcement) or outside the furthermost perimeter of shear reinforcement units. The punching loads, slab rotations at failure, and the failure modes (according to the regimes introduced in Fig. 2) are presented in Table 3.

Figure 8(a) compares the load-rotation curves of the slabs where the failure occurred close to the column plate. The load is presented as a nominal shear stress on a control perimeter located at distance $d / 2$ from the column face in accordance to the provisions of Model Code $2010^{4}$ (the U.S customary units' axes show the stress on a control perimeter with square corners as defined in ACI $318^{3}$; refer to the inserts in Fig. 8(a)). The curves have similar slopes, indicating that flexural stiffnesses of specimens were almost not influenced by the amounts and types of shear reinforcement. All specimens with shear reinforcement had clearly higher strengths and deformation capacities than a control specimen without shear reinforcement. However, the levels of load and rotation at the punching failure differed significantly, indicating varying efficiencies of the systems. It can also be observed that shear reinforcement ratio $\rho_{t}$ alone (Table 1) is insufficient to describe the punching capacity of the slab. As an example, the capacity of slab PB3 with individual links was clearly lower than that of PB2, where the links were anchored in blocks of UHPFRC, even though the shear reinforcement ratios and layouts of the reinforcement units were identical. This suggests that for sufficiently large amounts of shear reinforcement, the type of shear reinforcement (and 

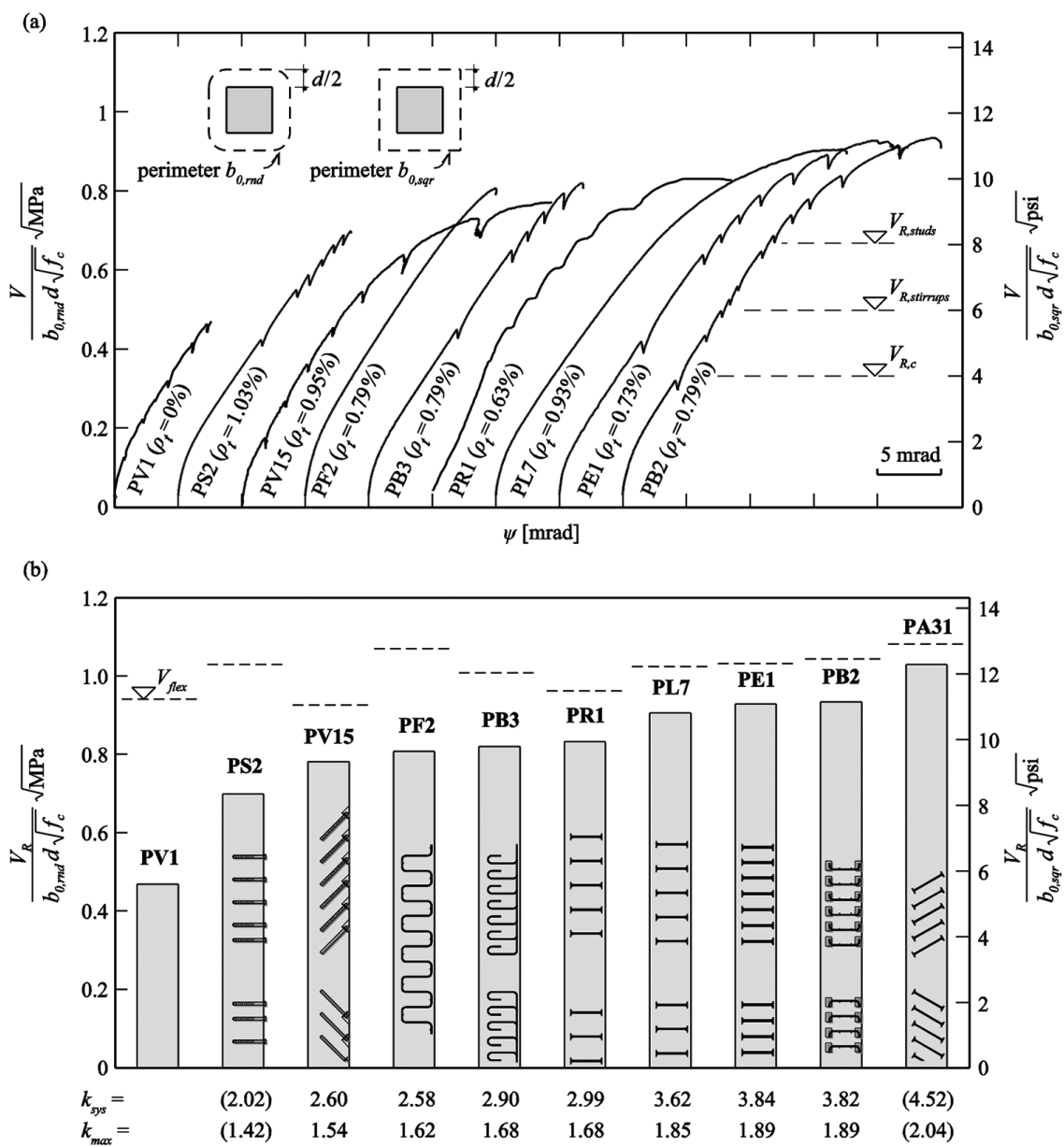

Fig. 8-Comparison of test results for slabs with different shear reinforcement systems: (a) load-rotation curves; and (b) normalized failure loads.

particularly its anchorage) governs the performance of a slab-column connection.

Figure 8(b) shows a comparison of the achieved punching strengths. Specimen PA31 with inclined double-headed studs, that failed outside of the shear-reinforced area but still showed the highest performance, is also added. Flexural strengths of specimens are shown for comparison purposes, calculated with the yield line method where the governing failure mechanism consists of a pair of parallel straight yield lines along the edges of the column in the direction of the outermost layer of reinforcement. ${ }^{21}$ Different flexural strengths of specimens arise from differences in yield strengths of rebars and some variations in the effective depths (measured after saw-cutting the slabs). Although the failures of some specimens took place close to their flexural limits (the load-rotation curves in Fig. 8(a) develop almost horizontally), their deformation capacities were clearly smaller than the rotation capacities associated with pure flexural failures. Therefore, such failures should still be treated as brittle punching failures, as will be discussed afterwards.

On the basis of these results, it can be observed that shear reinforcement systems with better anchorage conditions of the transverse reinforcement units (double-headed studs or UHPFRC blocks) show better performance (higher failure loads and larger deformation capacities) than the ones with poorer anchorage conditions (post-installed systems). Systems with inclined shear reinforcement also showed enhanced performance compared to similar systems with vertical shear reinforcement, as can be seen by comparing the two systems with post-installed reinforcement (PS2 and PV15) or the two slabs reinforced using double-headed studs (PL7 and PA31).

As seen on the saw-cuts (Fig. 9(a)), the slabs (especially the ones that underwent large rotations before failure) were heavily cracked in bending around the column. This confirms that punching is a combined phenomenon of bending and shear (as noted, among others, by Gardner and $\mathrm{Shao}^{22}$ ). That said, all failures occurred as a separation of a central cone by an inclined cracking zone, with a sudden drop of force to only approximately $30 \%$ of the maximum load and a penetration of the column plate into the slab (the post-punching residual capacity ${ }^{23}$ was not investigated further in the present research). Immediately before failure, yielding of the shear reinforcement could be measured ${ }^{2}$ in some units, but tensile ruptures of transverse bars were not observed in any of the specimens. The angle of the separated cone was lower for the slab without shear reinforcement (PV1) and for the slabs that failed outside of the shear reinforced area (PA31, PM1, and PT42) than for the slabs where the failure occurred in the shear-reinforced area (the rest of the slabs). For well-anchored shear reinforcement (like PL7), the failure surface was very steep and the concrete close to the column was 
(a)

PV1

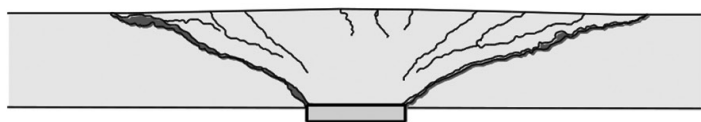

PS2

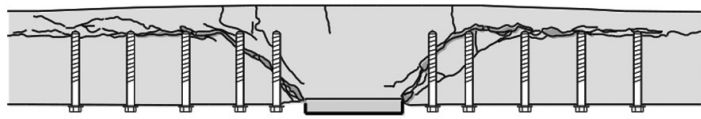

PF2

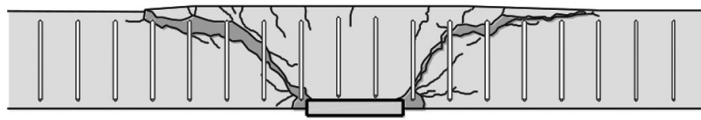

PB3

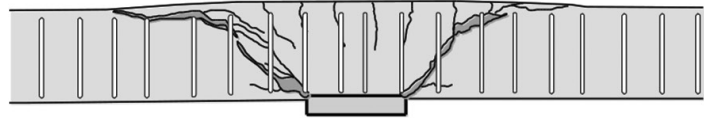

PR1

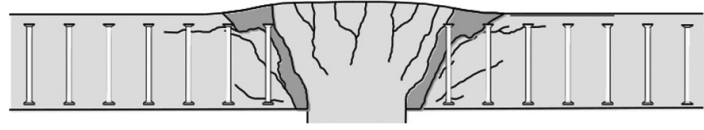

PL7

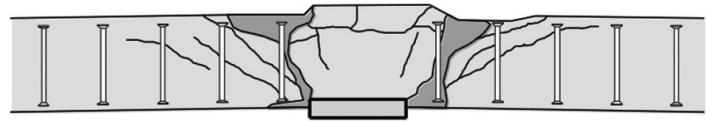

PB2

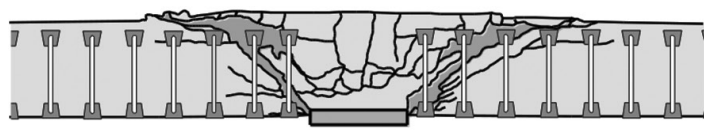

PE1*

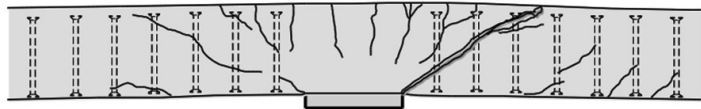

PV15

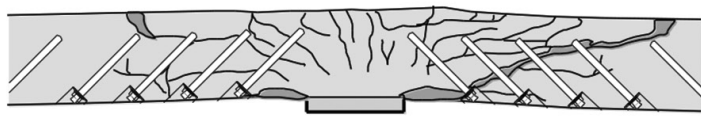

PA31

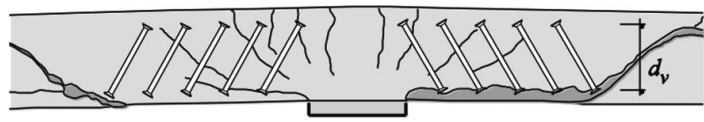

PM1

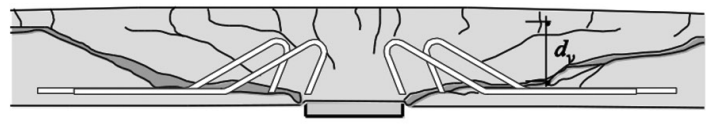

PT42

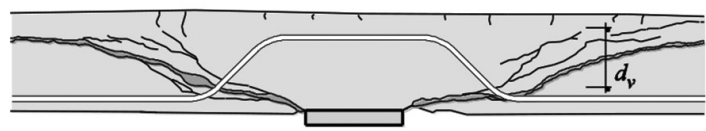

(b)

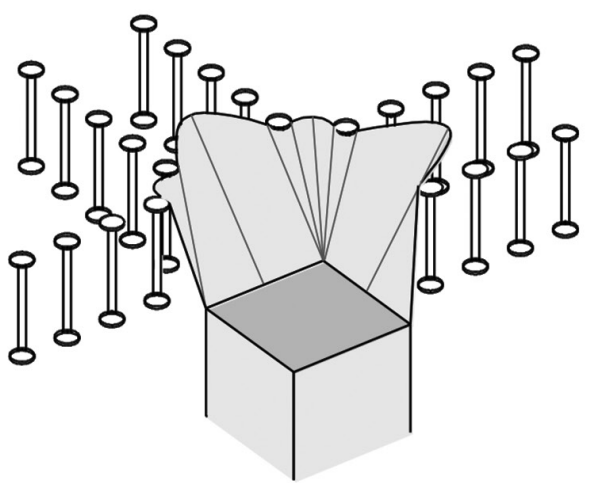

Fig. 9-Cracking patterns after failure: (a) cracks on saw-cuts; and (b) shape of failure surface of Specimen PE1. extensively crushed, whereas the concrete around the cracks of lower inclination was less damaged.

The cracking pattern of the slab with cruciform stud layout (PE1) was different from the cracking patterns of slabs with radial stud layouts. According to American practice (ACI $318^{3}$ ), the rows of studs were aligned with the corners of the support column so that the tangential spacing between the studs was approximately $260 \mathrm{~mm}$ (10.2 in.). As the specimens were cut along the axes, the failure crack seemed to have a relatively low inclination and crossed several shear studs. Closer examination revealed however that the inclination of the crack steepened closer to the studs and the crack did not cross shear reinforcement (Fig. 9(b)). However, for the column size and slab thickness used in the present campaign, this phenomenon did not seem to significantly affect the performance of the slab, as is shown by the similar failure loads and rotations of slabs PE1 and PL7. A similar observation has also been made by Birkle and Dilger. ${ }^{14}$

Failure outside the shear-reinforced area (Specimens PA31, PM1, and PT42) occurred as a separation of the shear reinforced zone by an inclined crack similar to the one in the slabs without shear reinforcement. The separation crack started from the lower end of the transverse reinforcement and not from the slab soffit.

\section{INTERPRETATION OF TEST RESULTS}

\section{Failure outside shear-reinforced area}

Failure outside of the shear-reinforced area occurs when the extent of such area is not sufficiently large. In this case, the resistance can be verified by checking the nominal stress on a critical perimeter located outside of the shear reinforced zone. In Model Code 2010, ${ }^{4}$ this perimeter is defined at a distance $d_{v} / 2$ from the last shear reinforcement unit. The reduced effective depth $d_{v}$ takes into account that the diagonal strut in the part of the slab without shear reinforcement has to be supported on the shear reinforcement. ${ }^{19}$ As the efficiency of the anchorage of these units may differ, different effective depths have to be defined for different systems (Fig. 10(a) to (d)). The length of the control perimeter is also limited in most design codes. For instance, if the distance between the bars on the outer perimeter is $>3 d$, only the parts of the control perimeter that are closer than $1.5 d$ to a transverse bar can be considered (Fig. 10(e) and (f)) according to Model Code 2010. In Eurocode $2,{ }^{5}$ the maximum allowed distance is $4 d$, whereas in ACI $318,{ }^{3}$ no limit is defined.

The failure cracks observed in the saw-cuts of Slabs PA31, PM1, and PT42 confirm that the cracks originate from the lower ends of the shear reinforcement units. The reduction of the effective depth to $d_{v}$ is therefore justified. In Eurocode $2,{ }^{5}$ the control perimeter for failure outside is located at $1.5 d$ from the last shear reinforcement perimeter that is closer than that of slabs without shear reinforcement, adopted at $2 d$ from the edge of the column. In ACI $318,{ }^{3}$ the perimeter for punching outside is defined at $0.5 d$ and no reduction of the effective depth is considered.

In practice, the failure mode outside of the shear-reinforced area is often governing for the systems where it is difficult to increase the number of perimeters of transverse units, as in the case of bent-up bars, where increasing the 
number of bars creates reinforcement congestion inside the column perimeter. This failure mode also often governs when slabs with studs arranged in a cruciform layout (following a common American practice and the rules of ACI $318^{3}$ ) are verified against the provisions of Eurocode $2^{5}$ or Model Code 2010. ${ }^{4}$ Figure 11 shows experimental to predicted punching strength ratios for slabs where the specimens had cruciform shear reinforcement layout and were reported as failing outside of the shear-reinforced area (PT42 and other similar tests gathered from the literature $\left.{ }^{11-14,24-27}\right)$. The predictions are plotted as a function of the distance from the

(a)

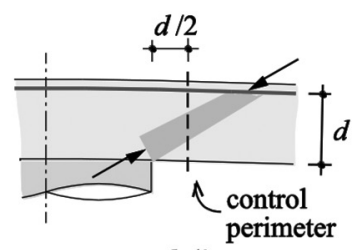

(c)

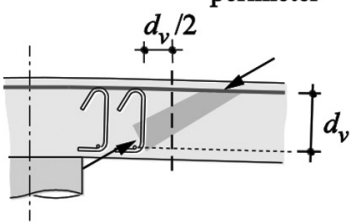

(e)

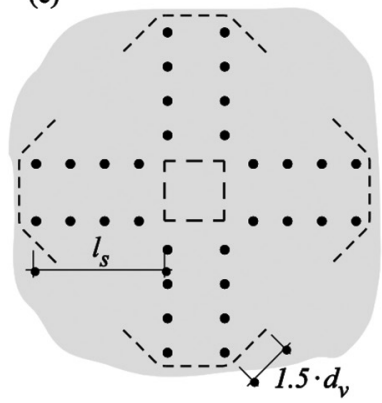

(b)

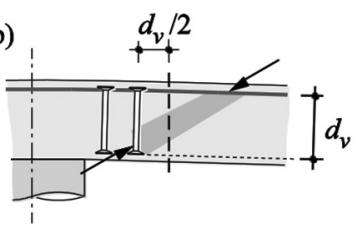

(d)

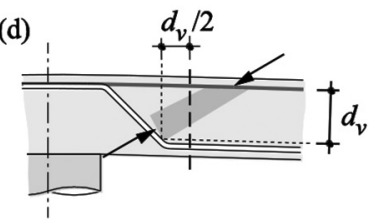

(f)

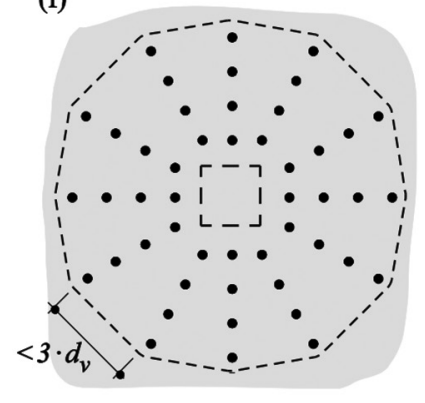

Fig. 10-Control perimeter and effective depth in case of failure outside shear reinforced area: (a) equivalent larger diameter column; (b) studs; (c) stirrups; (d) bent-up bars; (e) cruciform placement; and (f) radial placement.

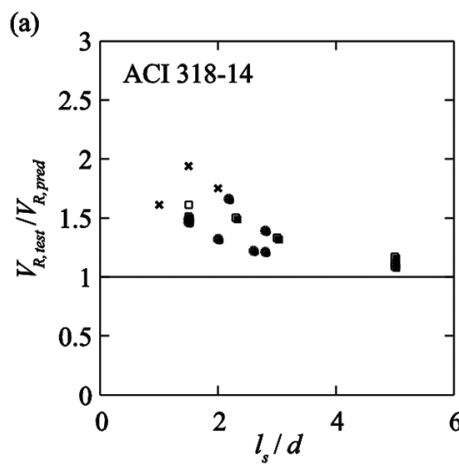

(b)

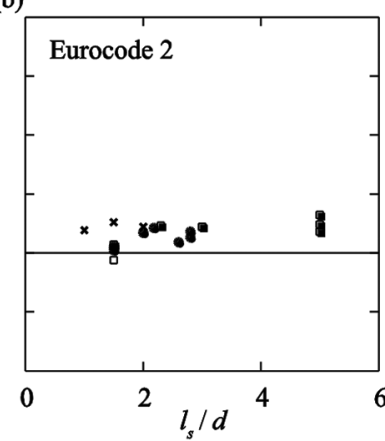

edge of the column to the farthest transverse bar. It can be seen that the predictions of ACI $318^{3}$ follow a clear trend with decreasing level of safety for larger shear-reinforced areas due to the increasing length of the parts of the of the outside control perimeter that are subtracted in other codes (Fig. 10(e)). No such trend can be observed for the predictions of Eurocode $2^{5}$ or Model Code $2010 .^{4}$

\section{Anchorage of shear reinforcement units}

Observing the cracking patterns on the saw-cuts of the slabs with post-installed shear reinforcement (PS2 in Fig. 9(a)), the failure crack appears to develop through the transverse reinforcement (concrete screws $\varnothing 19 \mathrm{~mm}$ [0.75 in.]) although the low level of load indicates that the screws had not reached yielding. This failure can be interpreted as an anchorage failure of the top ends of the transverse elements, leading to the opening of a failure crack. In these cases, increasing the number of elements may still increase the punching capacity but that increase is potentially lower than that of systems where efficient anchorage properties allow the shear reinforcement units reach yield stresses. In the CSCT-based calculation model, ${ }^{19}$ this failure can be predicted by modifying the bond conditions (slip) of the anchorage on two sides of the critical crack. However, this failure mode still demands additional investigation, as the bond conditions are influenced by transverse stresses and cracking due to bending of the specimen. In the present analysis, the results of Specimen PS2 are thus used to propose a conservative limit for the threshold of the maximum punching strength for such shear reinforcement systems.

\section{Influence of position of first shear reinforcement unit}

The failure inside the shear-reinforced zone can be described as a failure of a concrete strut between the first shear reinforcement unit and the column face ${ }^{19}$ (Fig. 2(c)). This strut has to transfer the force from the first transverse element to the column. The force in the strut increases with (c)

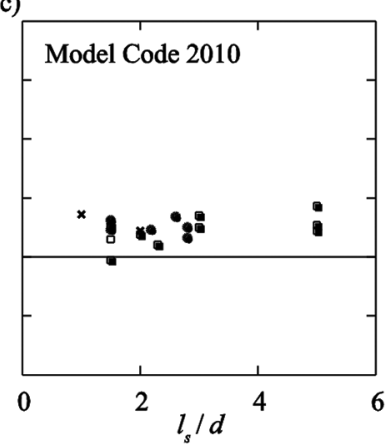

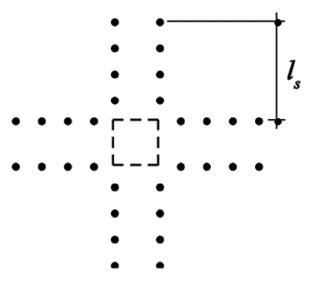

- double-headed studs ${ }^{14,24-27}$

- stirrups $^{11,13,26}$

$\times$ steel I-beam off-cuts ${ }^{12}$

- bent-up bars

Fig. 11-Comparison of experimental and predicted punching strengths of PT42 and specimens from literature ${ }^{11-14,24-27}$ with cruciform shear reinforcement layout failing outside shear reinforced area: (a) ACI 318; (b) Eurocode 2; and (c) Model Code 2010. 
lowering strut inclination. The inclination depends on the location and the anchorage conditions of the first transverse unit (with decreasing angles for longer distances from the first shear reinforcement to the supported area or poorer bond conditions). In addition, when the first transverse elements are located too close to the supported area, the force in the reinforcement may also not develop suitably due to low strains. Therefore, an optimal range exists for the location of the first shear reinforcement perimeter. The importance of that parameter has also been acknowledged in the codes: in ACI $318,{ }^{3}$ the maximum distance from the column face to the first shear reinforcement unit is $0.5 d$ (whereas the minimum distance is not given), the detailing rules of Eurocode $2^{5}$ require that the distance be from $0.3 d$ to $0.5 d$ and in Model Code $2010,{ }^{4}$ the minimum of that distance is set to $0.35 d$ and the maximum to $0.75 d$.

With respect to the influence of the position of the first studs, it may be a factor explaining the difference between the results of the slabs PL7 and PR1. In the case of PL7, the distance between the column edge and the first stud perimeter was $0.41 d$, whereas the distance of $0.57 d$ in PR1 did not meet the ACI $318^{3}$ and Eurocode $2^{5}$ requirements. The nominal experimental strength at failure of PR1 was $8 \%$ lower compared to PL7.

\section{Efficiency of shear reinforcement}

As shown by the experimental results, the performance of various shear reinforcement systems can be quite different. This difference has also been acknowledged in some codes of practice. The punching provisions of ACI $318^{3}$ distinguish between stirrups, double-headed studs, and structural steel shearheads and define different limits on the allowed nominal shear stress depending on the system. The limits for studs and stirrups are shown together with the experimental results in Fig. 8(a).

The punching provisions of Model Code $2010^{4}$ are based on the $\operatorname{CSCT}^{1}$ and thus acknowledge the differences between various systems through factor $k_{s y s}$ that modulates the maximum punching capacity criterion governing for large shear reinforcement ratios ${ }^{19}$ (Fig. 2(c)). The value of $k_{s y s}$ has to be determined for each system by performing a campaign of full-scale punching tests. In the absence of specific data, $k_{s y s}=2.4$ can be used for stirrups and 2.8 for double-headed studs. ${ }^{4}$ It should be noted that the influence of $k_{\text {sys }}$ on punching strength is not linear (refer to Fig. 12 where the predicted strength is given as a function of $k_{s y s}$ ).

The calculated values of $k_{s y s}$ (with the equations given in Appendix A) are given in Table 3 and in Fig. 8(b). The $k_{s y s}$ values for Specimens PS2, PA31, PM1, and PT42 are given in parentheses, as the strength was limited by anchorage of the post-installed reinforcement (for PS2) or by punching outside of the shear-reinforced area in these specimens. Thus, higher values of parameter $k_{s y s}$ can potentially be attained for these systems and the provided values can be interpreted as a lower bound of this parameter. The tests presented in this paper suggest that values around 2.6 may be suitable for stirrups, whereas $k_{s y s}$ can even be larger than 3.6 for studs when the spacing rules regarding the distance from the first stud to the column are respected. The efficiency of post-installed

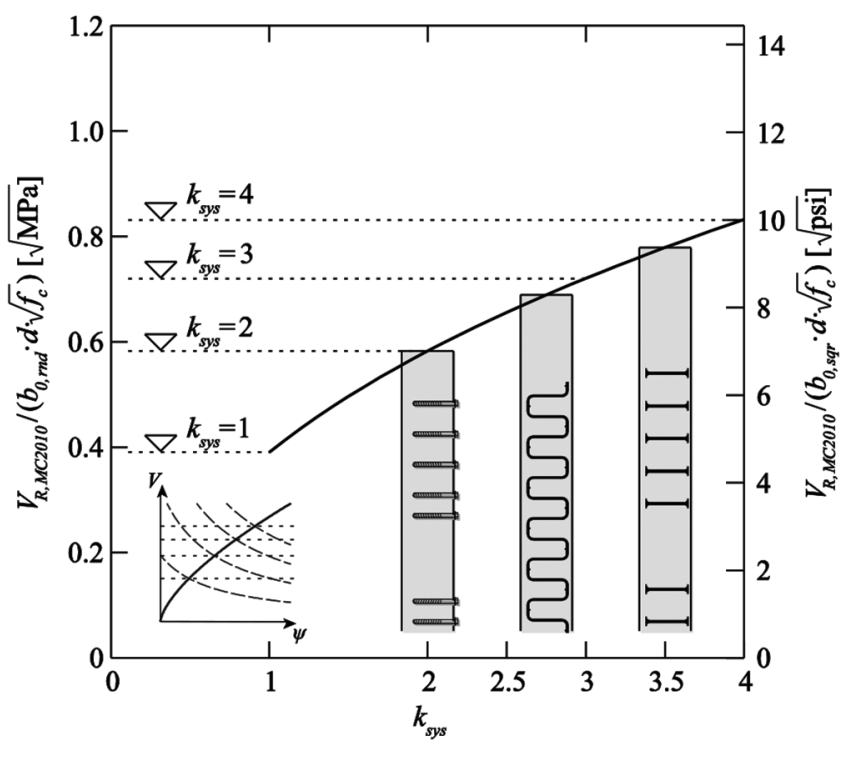

Fig. 12-Influence of factor $\mathrm{k}_{\mathrm{sys}}$ on punching strength, according to Model Code 2010 (for parameters of reference slab, refer to Fig. 3).

systems is lower (between 2.0 and 2.6) and depends significantly on the anchorage and bond properties.

In an amendment to Eurocode $2^{5}$ published in 2014, a new factor $k_{\max }$ has been introduced that limits the strength of a shear-reinforced concrete slab to a multiple of the strength of a similar slab without shear reinforcement. The recommended value of $k_{\max }$ is 1.5 but higher values (up to 1.9 for double-headed studs ${ }^{6}$ ) may be used if they are supported by experimental evidence. The values of $k_{\max }$ calculated from the results of the presented tests are also given in Table 3 and Fig. 8(b) (the use of parentheses should be interpreted in the same manner as for $\left.k_{s y s}\right)$. Contrary to the parameter $k_{s y s}, k_{\max }$ influences the predicted punching strength of specimens linearly. According to the present study, for specimens with double-headed studs, the values of $k_{\max }$ remain above 1.8 , whereas for stirrups, values close to 1.6 are obtained. Again, the efficiency of post-installed shear reinforcement may vary significantly.

\section{INTERACTION BETWEEN FLEXURAL AND SHEAR STRENGTHS}

In the cases when punching governs the strength, the slab-column connections usually show limited deformation capacities unless very low amounts of flexural reinforcement or fairly large support areas are used. Thus, the design methods that are based on the theory of plasticity can only be applied with careful evaluation of the possible differences between assumed and actual distributions of internal forces. As shown in Fig. 8(a), using shear reinforcement increases not only the strength but also the deformation capacity of slab-column connections and thus allows for larger redistributions of internal forces. Also, such structures are less sensitive to imposed displacements (such as foundation settlements), exhibit larger deformations before failure (providing warning signs of malfunction) and may help to avoid progressive collapse in the case of a failure of a supporting structural element. 

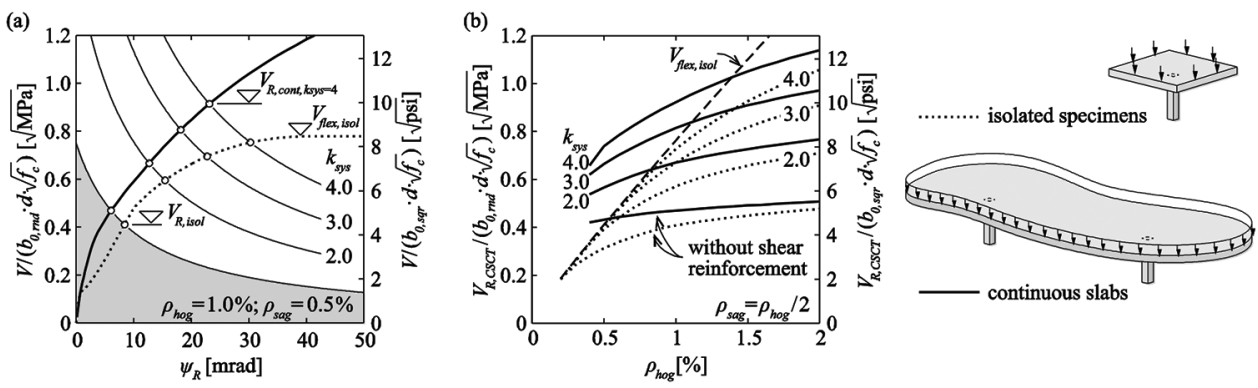

Fig. 13-Punching of continuous slabs: (a) load-rotation curves for isolated and continuous self-confined slabs (hogging reinforcement ratio $1.0 \%$; sagging reinforcement ratio $0.5 \%$ ); and (b) punching strengths of isolated and continuous self-confined slabs with different types of shear reinforcement $\left(\mathrm{k}_{\mathrm{sys}}=2.0\right.$ to 4.0) depending on flexural reinforcement ratio. For parameters, refer to Fig. 3, unless shown otherwise.

In a study on axisymmetric continuous slabs, Einpaul et al. ${ }^{28}$ have shown that considerable redistribution between hogging and sagging moments may occur before a punching failure. Thus, the local bending moment concentrations that appear in the vicinity of the columns according to elastic distribution of internal forces can be redistributed within the slab, provided that the slab has sufficient deformation capacity. In addition, due to dilation of the cracked slab portion around the column that is confined by the surrounding uncracked slab parts, compressive membrane forces that increase its flexural stiffness are self-generated in the slab. These phenomena decrease the slab rotation $\psi$ at a given level of load compared to a corresponding isolated specimen (Fig. 13(a)) and thus increase the punching strength.

On the basis of a numerical model that was validated by comparing its predictions to the results of various unconventional punching tests, ${ }^{28}$ Fig. 13(b) shows a parametric analysis on the punching strength of isolated specimens and continuous slabs with varying amounts of hogging reinforcement. The calculations are performed for slabs with different shear reinforcement systems characterized by different values of $k_{s y s}(2.0$ to 4.0$),{ }^{19}$ accounting for redistribution between hogging and sagging moments as well as compressive membrane action. The differences between continuous slabs and axisymmetric isolated specimens are more important for lower flexural reinforcement ratios, as in these cases, flexural reinforcement reaches yielding before a punching failure in a large part of the specimen. In a corresponding continuous slab, the hogging bending moments in the vicinity of the column are redistributed to the sagging moments in mid-span, thereby decreasing the size of the hogging moment area. This effect cannot appear in isolated specimens. Therefore, isolated specimens reach a flexural limit at lower load levels. Thus, a punching failure that occurs close to the flexural limit of a test specimen does not directly represent the strength of a corresponding actual, continuous slab. However, if the deformation capacity of the specimens is investigated as well, the strength of corresponding actual slabs can also be predicted owing to the physical basis of the CSCT.

\section{CONCLUSIONS}

This paper presents the results of one slab without shear reinforcement and 11 slabs with identical geometrical param- eters but different systems of shear reinforcement tested to failure by punching. The results were analyzed using the Critical Shear Crack Theory as well as some codes of practice and the following conclusions were made.

1. Using shear reinforcement increases not only the punching strength but also the deformation capacity of a flat slab. Above a certain threshold of shear reinforcement ratio, the punching strength is independent of the amount of shear reinforcement as it is associated to a failure of the concrete struts between the column face and shear reinforcement units. The experimental data presented in this paper confirm that the type of shear reinforcement, its spacing, and anchorage conditions strongly influence the performance of the slab-column connections in this failure mode.

2. The type of shear reinforcement should be taken into account in the design of slabs against punching shear. This is consistent with the approach followed by ACI 318 and Model Code 2010.

3 . For the different shear reinforcement systems investigated in the present test campaign, the factor $k_{s y s}$ describing the performance of a system in Model Code 2010 varied between 2.0 and 3.8 (up to 4.5 in special cases), with higher values associated to slabs with headed studs.

4. The factor $k_{\max }$, recently introduced in Eurocode 2 to account for the influence of punching shear reinforcement on the maximum punching shear strength, is also observed to depend on the type of transverse reinforcement. The calculated values of this parameter for the present tests varied between 1.4 and 1.9 with higher values associated again to slabs with headed studs.

5. Tests with radial and cruciform arrangements of shear reinforcement showed similar performances regarding the maximum punching capacity. For uneven spacing of shear reinforcement close to the column, the failure crack may obtain a lower angle in the areas too far from the transverse elements. These parts may have to be discounted from the length of the verification perimeter.

6. For failures outside the shear-reinforced area, the shear-resisting effective depth should not include the parts of concrete below the anchorage zone of shear reinforcement, as the failure crack will develop from the bottom end of transverse elements and not from the slab soffit.

7. In the case of large spacing of shear reinforcement units at the outermost perimeter (as for shear reinforcement 
arranged in cruciform layout), the length of the verification perimeter for failure outside of the shear-reinforced area should be reduced.

8. Punching strengths obtained at load levels close to the flexural limit of an isolated test specimen may not be directly valid for actual continuous slabs. The CSCT provides a physical basis for estimating the capacities of actual slabs based on the test results of isolated specimens, accounting for moment redistributions and membrane effects.

\section{AUTHOR BIOS}

Jürgen Einpaul is a Structural Engineer at Estkonsult, Tallinn, Estonia. He received his PhD from École Polytechnique Fédérale de Lausanne (EPFL), Lausanne, Switzerland, in 2016. His research interests include the mechanics of axisymmetric as well as non-axisymmetric punching shear failures of reinforced concrete slabs and the behavior of continuous slabs.

Fabio Brantschen is a Research Assistant and PhD Candidate at the School of Architecture, Civil, and Environmental Engineering (ENAC) of EPFL. He received his MS from EPFL in 2011. His research interests include performance of different anchorage systems and punching of slabs with shear reinforcement.

Miguel Fernández Ruiz is a Lecturer and Research Scientist at EPFLENAC. He was the co-recipient of the ACI Wason Medal for Most Meritorious Paper in 2014. His research interests include the serviceability behavior of structures, bond, shear and punching shear, and the modeling of structural concrete using stress fields.

ACI member Aurelio Muttoni is a Professor and Head of the Structural Concrete Laboratory at the EPFL-ENAC. He was the recipient of the ACI Chester Paul Siess Award for Excellence in Structural Research in 2010 and the co-recipient of the Wason Medal for Most Meritorious Paper in 2014. His research interests include the theoretical bases of the design of reinforced concrete structures, shear and punching shear, fiber-reinforced high-strength concrete, soil-structure interaction, and the conceptual design of bridges.

\section{ACKNOWLEDGMENTS}

The authors would like to thank the following punching shear reinforcement manufacturers for allowing us to publish the experimental data presented within this paper: Ancotech AG (test PE1), Bossard+Staerkle AG (tests PB2 and PB3), Halfen-DEHA (test PR1), Fischer-Rista (test PF2), SFS intec (test PS2), and Hilti AG (tests PV1 and PV15).

This research has also been funded by the Swiss National Science Foundation, Projects No. 121566 and No. 137658. The authors are appreciative of the support received.

\section{REFERENCES}

1. Muttoni, A., "Punching Shear Strength of Reinforced Concrete Slabs Without Transverse Reinforcement," ACI Structural Journal, V. 105, No. 4, July-Aug. 2008, pp. 440-450.

2. Lips, S.; Fernández Ruiz, M.; and Muttoni, A., "Experimental Investigation on Punching Strength and Deformation Capacity of Shear-Reinforced Slabs," ACI Structural Journal, V. 109, No. 6, Nov.-Dec. 2012, pp. 889-900.

3. ACI Committee 318, "Building Code Requirements for Structural Concrete (ACI 318-14) and Commentary (ACI 318R-14)," American Concrete Institute, Farmington Hills, MI, 2014, 530 pp.

4. Fédération internationale du béton, "fib Model Code for Concrete Structures 2010," Ernst \& Sohn, Berlin, Germany, 2013, 434 pp.

5. EN 1992-1-1:2014, "Design of Concrete Structures_-Part 1: General Rules and Rules for Buildings (Including the Amendment A1:2014)," European Committee for Standardization, Brussels, Belgium, 2004, 225 pp.

6. Beutel, R., and Hegger, J., "The Effect of Anchorage on the Effectiveness of the Shear Reinforcement in the Punching Zone," Cement and Concrete Composites, V. 24, No. 6, 2002, pp. 539-549. doi: 10.1016/ S0958-9465(01)00070-1
7. Yamada, T.; Nanni, A.; and Endo, K., "Punching Shear Resistance of Flat Slabs: Influence of Reinforcement Type and Ratio," ACI Structural Journal, V. 88, No. 5, Sept.-Oct. 1992, pp. 555-563.

8. Pérez Caldentey, A.; Padilla, P.; Corres Peiretti, H.; and Ariñez Fernández, F., "Influence of Stirrup Detailing on Punching Shear Strength of Flat Slabs," Engineering Structures, V. 49, 2013, pp. 855-865. doi: 10.1016/j.engstruct.2012.12.032

9. Papanikolaou, K. V.; Tegos, I. A.; and Kappos, A. J., "Punching Shear Testing of Reinforced Concrete Slabs and Design Implications," Magazine of Concrete Research, V. 57, No. 3, 2005, pp. 167-177. doi: 10.1680/ macr.2005.57.3.167

10. Broms, C. E., "Ductility of Flat Plates: Comparison of Shear Reinforcement Systems," ACI Structural Journal, V. 104, No. 6, Nov.-Dec. 2007, pp. 703-711.

11. Oliveira, D. R.; Melo, G. S.; and Regan, P. E., "Punching Strengths of Flat Plates with Vertical or Inclined Stirrups," ACI Structural Journal, V. 97, No. 3, May-June 2000, pp. 485-491

12. Gomes, R. B., and Regan, P. E., "Punching Strength of Slabs Reinforced for Shear with Offcuts of Rolled Steel I-Section Beams," Magazine of Concrete Research, V. 51, No. 2, 1999, pp. 121-129. doi: 10.1680/ macr.1999.51.2.121

13. Vollum, R. L.; Abdel-Fattah, T.; Eder, M.; and Elghazouli, A., "Y., "Design of ACI-Type Punching Shear Reinforcement to Eurocode 2," Magazine of Concrete Research, V. 62, No. 1, 2010, pp. 3-16. doi: 10.1680/ macr.2008.62.1.3

14. Birkle, G., and Dilger, W. H., "Shear Strength of Slabs with DoubleHeaded Shear Studs in Radial and Orthogonal Layouts," Thomas T.C. Hsu Symposium: Shear and Torsion in Concrete Structures, SP-265, American Concrete Institute, Farmington Hills, MI, 2009, pp. 499-510.

15. Feix, J.; Wörle, P.; and Gerhard, A., "Ein Neuer Ansatz zur Steigerung der Durchstanztragfähigkeit Bestehender Stahlbetonbauteile [A New Method to Enhance the Shear Punching Capacity of Existing Concrete Structures],' Der Bauingenieur, V. 87, No. 4, 2012, pp. 149-155. (in German)

16. Wörle, P., "Enhanced Shear Punching Capacity by the Use of Post Installed Concrete Screws," Engineering Structures, V. 60, 2014, pp. 41-51. doi: 10.1016/j.engstruct.2013.12.015

17. Fernández Ruiz, M.; Muttoni, A.; and Kunz, J., "Strengthening of Flat Slabs Against Punching Shear Using Post-Installed Shear Reinforcement," ACI Structural Journal, V. 107, No. 4, July-Aug. 2010, pp. 434-442.

18. Einpaul, J.; Bujnak, J.; Fernández Ruiz, M.; and Muttoni, A., "Study on the Influence of Column Size and Slab Slenderness on Punching Strength," ACI Structural Journal, V. 113, No. 1, Jan.-Feb. 2016, pp. 135-146.

19. Fernández Ruiz, M., and Muttoni, A., "Applications of the Critical Shear Crack Theory to Punching of Reinforced Concrete Slabs with Transverse Reinforcement," ACI Structural Journal, V. 106, No. 4, July-Aug. 2009, pp. 485-494

20. Muttoni, A., and Fernández Ruiz, M., "Reinforcement element for structural concrete construction," International patent no. WO/2010/116323 A1, publication date Oct. 14, 2010

21. Guidotti, R.; Fernández Ruiz, M.; and Muttoni, A., "Crushing and Flexural Strength of Slab-Column Joints," Engineering Structures, V. 33, No. 3, 2011, pp. 855-867. doi: 10.1016/j.engstruct.2010.12.007

22. Gardner, N. J., and Shao, X., "Punching Shear of Continuous Flat Reinforced Concrete Slabs," ACI Structural Journal, V. 93, No. 2, Mar.-Apr. 1996, pp. 218-228.

23. Fernández Ruiz, M.; Mirzaei, Y.; and Muttoni, A., "Post-Punching Behavior of Flat Slabs," ACI Structural Journal, V. 110, No. 5, Sept.-Oct. 2013, pp. 801-812.

24. Stein, T.; Ghali, A.; and Dilger, W. H., "Distinction between Punching and Flexural Failure Modes of Flat Plates," ACI Structural Journal, V. 104 No. 3, May-June 2007, pp. 357-365.

25. Marzouk, H., and Jiang, D., "Experimental Investigation on Shear Enhancement Types for High-Strength Concrete Plates," ACI Structural Journal, V. 94, No. 1, Jan.-Feb. 1997, pp. 49-58.

26. Seible, F.; Ghali, A.; and Dilger, W. H., "Preassembled Shear Reinforcing Units for Flat Plates," ACI Journal Proceedings, V. 77, No. 1, Jan.-Feb. 1980, pp. 28-35.

27. Rizk, E.; Marzouk, H.; and Hussein, A., "Punching Shear of Thick Plates with and without Shear Reinforcement," ACI Structural Journal, V. 108, No. 5, Sept.-Oct. 2011, pp. 581-591.

28. Einpaul, J.; Fernández Ruiz, M.; and Muttoni, A., "Influence of Moment Redistribution and Compressive Membrane Action on Punching Strength of Flat Slabs," Engineering Structures, V. 86, 2015, pp. 43-57. doi: 10.1016/j.engstruct.2014.12.032 


\section{APPENDIX A}

This appendix describes the provisions of main codes of practice ${ }^{\text {Error! Reference source not found.Error! }}$ Reference source not found..Error! Reference source not found. for calculating the punching shear capacity of a symmetric interior slab-column connection. In this appendix, all safety factors are taken equal to 1.

In all the considered codes, the punching resistance is verified by comparing a nominal stress $v$ on a control section to a nominal shear strength $v_{R}$ of that section. The shear stress is defined as: $v=V /\left(b_{0} \cdot d\right)$

where $V$ is the concentrated load, $b_{0}$ is the control perimeter (its definition varies between the codes) and $d$ is the effective depth of the slab (mean value of the two main directions).

\section{ACI 318}

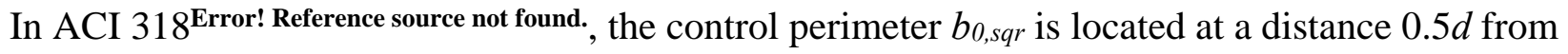
the column edge. In the case of square or rectangular columns, the corners of the control perimeter are not rounded.

For square interior columns with $c<4 d$ and normal strength concrete, the concrete contribution to the nominal shear strength is calculated as:

$v_{R, c, A C I}=0.33 \cdot f_{c}^{1 / 2}[$ SI units $]$

$v_{R, c, A C I}=4 \cdot f_{c}^{1 / 2}[$ in.-lb units $]$

where $f_{c}$ is the concrete cylinder compressive strength in MPa [psi].

Punching shear strength of shear-reinforced slabs is:

$v_{R, c s}=0.5 \cdot v_{R, c, A C I}+\rho_{t} \cdot f_{y t} \leq 1.5 \cdot v_{R, c, A C I}$

In the case of double-headed studs (also complying with stricter detailing rules ${ }^{\text {Error! Reference source }}$ not found.): 
$v_{R, c s}=0.75 \cdot v_{R, c, A C I}+\rho_{t} \cdot f_{y t} \leq 2 \cdot v_{R, c, A C I}$

Shear reinforcement ratio $\rho_{t}$ is defined as:

$\rho_{t}=A_{v} /\left(b_{0, s q r} \cdot s_{t}\right)$

where $A_{v}$ is total reinforcement area on one perimeter of shear reinforcement units and $s_{t}$ is radial spacing between the perimeters.

\section{Eurocode 2}

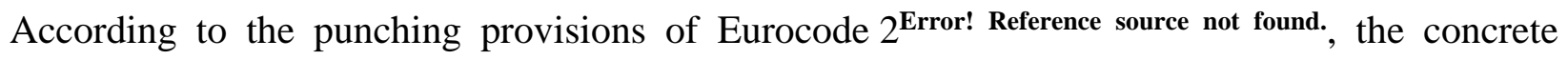
contribution to the nominal shear strength at a control perimeter with a length $b_{0,2 d}$ located at a distance $2 d$ from the edge of the loaded area is:

$$
\begin{aligned}
& v_{R, c, E C 2}=0.18 \cdot k \cdot(100 \cdot \rho)^{1 / 3} \cdot f_{c}^{1 / 3} \geq 0.035 \cdot k^{3 / 2} \cdot f_{c}^{1 / 2} \text { [SI units] } \\
& v_{R, c, E C 2}=5.0 \cdot k \cdot(100 \cdot \rho)^{1 / 3} \cdot f_{c}^{1 / 3} \geq 0.42 \cdot k^{3 / 2} \cdot f_{c}^{1 / 2} \text { [in.-lb units] }
\end{aligned}
$$

where $\rho$ is the flexural reinforcement ratio (geometric mean of two perpendicular directions, taken at most 2.0\%, $f_{c}$ is the concrete cylinder compressive strength in MPa [psi] and $k=(1+\sqrt{200 \mathrm{~mm}[7.87 \mathrm{in} .] / d}) \leq 2$ is a size effect factor.

Nominal shear strength of slabs with shear reinforcement is (according to an amendment of Eurocode 2 published in 2014):

$$
v_{R, c s}=0.75 \cdot v_{R, c, E C 2}+1.5 \cdot \rho_{t, E C 2} \cdot f_{y t, e f} \cdot \sin \alpha \leq k_{\max } \cdot v_{R, c, E C 2}
$$

where $\alpha$ is an angle between the shear reinforcement units and the plane of the slab, the effective yield strength of shear reinforcement units is $f_{y t, e f}=1.15 \cdot(250+0.25 \cdot d)[\mathrm{MPa}, \mathrm{mm}]$ or $f_{y t, e f}=1.15 \cdot(36+0.92 \cdot d)[\mathrm{ksi}, \mathrm{in}$.$] and k_{\max }$ is a factor introduced in an amendment published in 2014 (recommended value of $k_{\max }$ is 1.5 but higher values may be used if they are experimentally validated). 
Shear reinforcement ratio $\rho_{t, E C 2}$ is defined as:

$\rho_{t, E C 2}=A_{v} /\left(b_{0,2 d} \cdot s_{t}\right)$

An additional verification has to be performed at the edge of the loaded area, where the shear stress has to be lower than (according to an amendment of Eurocode 2 published in 2010):

$$
\begin{aligned}
& v_{R, E C 2(0 d)}=0.24 \cdot\left(1-\frac{f_{c}}{250}\right) \cdot f_{c}[\text { SI units }] \\
& v_{R, E C 2(0 d)}=0.24 \cdot\left(1-\frac{f_{c}}{36200}\right) \cdot f_{c} \text { [in.-lb units] }
\end{aligned}
$$

\section{Model Code 2010}

The punching provisions of Model Code 2010 Error! Reference source not found. are based on the Critical Shear Crack Theory Error! Reference source not found. (CSCT). The control perimeter $b$,rnd is located at a distance $0.5 d$ from the column edge. The corners of a control perimeter around a square column have to be rounded.

According to the CSCT, the nominal punching strength on a control section is a function of slab rotation $\psi$ :

$$
\begin{aligned}
& v_{R, c, C S C T}=\frac{3 / 4}{1+15 \cdot \frac{\psi \cdot d}{d_{g}+d_{g 0}}} \cdot f_{c}^{1 / 2}[\text { SI units] } \\
& v_{R, c, C S C T}=\frac{4}{0.44+6.67 \cdot \frac{\psi \cdot d}{d_{g}+d_{g 0}}} \cdot f_{c}^{1 / 2} \text { [in.-lb units] }
\end{aligned}
$$

where $d_{g}$ is the maximum aggregate size in $\mathrm{mm}$ [in.] and $d_{g} 0$ is a reference aggregate size of $16 \mathrm{~mm}$ [0.63 in.]. The failure criterion was validated with 99 tests from the literature and it was calibrated to provide a mean value of the test capacities. 
For Model Code 2010, the failure criterion was modified in order to correspond to the characteristic value of the test results:

$v_{R, c, M C 2010}=\frac{1}{1.5+0.9 \cdot \psi \cdot d \cdot k_{d g}} \cdot f_{c}^{1 / 2}[$ SI units $]$

$v_{R, c, M C 2010}=\frac{4}{0.5+7.5 \cdot \psi \cdot d \cdot k_{d g}} \cdot f_{c}^{1 / 2}[$ in.-lb units]

where $k_{d g}=2 /\left(1+d_{g} / d_{g 0}\right) \geq 0.75, d_{g 0}=16 \mathrm{~mm}[0.63$ in.].

In axisymmetric cases, the relationship between the applied load $V$ and slab rotation $\psi$ can be calculated by integrating the tangential moments between the center of the column and the line of moment contraflexure Error! Reference source not found.: $^{2}$

$V=\frac{2 \pi}{r_{q}-r_{c}} \cdot \int_{r=0}^{r=r_{s}} m_{\text {tang, }, i}(\chi) d r$

where $r_{q}$ is the distance between the center of the column and the resultant of the load applied on a slab sector, the radius of the column $r_{c}$ is taken as half of the column side length in the case of square columns and $r s$ is the distance between the center of the column and the line of moment contraflexure, taken as half of side length in the case of square specimens. Tangential moment $m_{\text {tang }}$ is calculated using a 4-linear moment-curvature law Error! Reference source not found. from curvatures:

$\chi_{\text {tang, }, i}=-\psi / r_{i} \geq-\psi / r_{0}$

where $\psi$ is slab rotation and $r_{0}$ is the distance from the center of the slab to the point where the inclined critical shear crack reaches the level of flexural reinforcement, taken as $r_{0}=r_{c}+d \cdot \tan 45^{\circ}$. 
According to Model Code 2010, the load-rotation relationship can be estimated in a simplified manner. In Level of Approximation II (recommended for a typical design of new structures), slab rotation can be estimated with a relationship that depends on the acting moment in the column strip:

$\psi=1.5 \cdot \frac{r_{s}}{d} \cdot \frac{f_{y}}{E_{s}} \cdot\left(\frac{m_{S}}{m_{R}}\right)^{3 / 2}$

where $r_{s}$ is the radius of an isolated slab (taken as half of the side length for square specimens) or $0.22 L$ in case of a continuous slab with regular span lengths, $f_{y}$ and $E_{s}$ are the yield strength and modulus of elasticity of flexural reinforcement, respectively, $m_{R}$ is the moment capacity of the slab and $m_{S}$ is the average acting moment in the column strip that, for interior columns in slabs with sufficiently regular geometry, can be approximated as $m_{S}=V / 8$.

In the case of slabs with shear reinforcement, the reinforcement contribution is accounted for by adding to the concrete contribution the stresses in the reinforcement units that cross the critical crack $^{\text {Error! Reference source not found.: }}$

$v_{R, c s}=v_{R, c}(\psi)+\rho_{t} \cdot \sigma_{s t}(\psi) \leq k_{s y s} \cdot v_{R, c, C S C T}(\psi)$

where $\rho_{t}=A_{v} /\left(b_{0, r n d} \cdot s_{t}\right)$ and $k_{s y s}$ is a parameter that depends on the type of shear reinforcement and describes the maximum punching resistance.

Stress in shear reinforcement can be calculated as:

$\sigma_{s t}=\frac{E_{s} \psi}{6}\left(1+\frac{f_{b}}{f_{y t}} \frac{d}{\Phi_{t}}\right) \leq f_{y t}$

where $E_{s}$ is the modulus of elasticity, $f_{b}$ is the bond strength, $f_{y t}$ is the yield strength and $\Phi_{t}$ the diameter of the shear reinforcement units. In Model Code 2010, the recommended values of $k_{s y s}$ are 2.4 for stirrups and 2.8 for double-headed studs. 
In the case of a failure outside of the shear-reinforced area, the nominal stress has to be calculated accounting for a shear-resisting effective depth $d_{v}$ and a control perimeter is located at a distance $d_{v} / 2$ from the last perimeter of shear reinforcement units (refer to Fig. 10). 


\section{APPENDIX B}

The following symbols are used in the paper:

$A_{v} \quad=$ total reinforcement area on one perimeter of shear reinforcement units

$b_{0, \text { rnd }}=$ length of a control perimeter according to Model Code 2010 (with rounded corners)

$b_{0, s q r}=$ length of a control perimeter according to ACI 318 (with square corners)

$d \quad=$ effective depth (distance from the most compressed fiber to the centroid of tension reinforcement)

$d_{g} \quad=$ maximum aggragate size

$d_{v} \quad=$ shear-resisting effective depth

$f_{c} \quad=$ cylinder compressive strength of concrete

$f_{y} \quad=$ yield stress of flexural reinforcing steel

$f_{y t} \quad=$ yield stress of shear reinforcement units

$k_{\max }=$ factor that limits the maximum increase of shear capacity for slabs with shear reinforcement in Eurocode 2 (amended in 2014)

$k_{\text {sys }} \quad=$ factor describing the maximum punching shear strength in Model Code 2010

$l_{s} \quad=$ distance from the edge of the column to the furthest shear reinforcement unit

$n_{\text {tang }}=$ number of shear reinforcement units in one perimeter

$n_{\text {rad }}=$ number of perimeters of shear reinforcement units

$n_{x}, n_{y}=$ number of shear reinforcement units in $x$ and $y$ directions

$s_{0} \quad=$ distance between the edge of the column and the first perimeter of shear reinforcement units 
$s_{1} \quad=$ spacing between the first and the second perimeter of shear reinforcement units

$s_{n} \quad=$ spacing between subsequent shear reinforcement units’ perimeters

$s_{x}, s_{y}=$ spacing between shear reinforcement units along $x$ and $y$ directions

$V \quad=$ applied concentrated load

$V_{\text {flex }} \quad=$ applied concentrated load associated to flexural capacity

$V_{R} \quad=$ punching capacity

$V_{R, c} \quad=$ concrete contribution to the punching capacity

$V_{R, c s} \quad=$ punching capacity of a slab with shear reinforcement

$V_{R, \text { out }}=$ punching capacity for failure outside of shear-reinforced area

$w \quad=$ width of the critical shear crack

$\rho_{\text {flex }}=$ flexural reinforcement ratio

$\rho_{\text {hog }} \quad=$ hogging (negative) flexural reinforcement ratio

$\rho_{\text {sag }} \quad=$ sagging (positive) flexural reinforcement ratio

$\rho_{t} \quad=$ shear reinforcement ratio $\left(\rho_{t}=A_{v} /\left[b_{0, \text { rnd }} \cdot \max \left(s_{0}+s_{I} / 2 ; s_{I}\right)\right]\right)$

$\sigma_{s t} \quad=$ stress in shear reinforcement

$\psi \quad=$ slab rotation

$\psi_{R} \quad=$ slab rotation at punching failure

$\Phi_{t} \quad=$ diameter of shear reinforcement units 